\title{
Age-related cellular reactions to copper in the marine mussel Mytilus edulis
}

\author{
Lisa M. Hole ${ }^{1,2, *}$, Michael N. Moore ${ }^{1}$, Denis Bellamy ${ }^{2}$ \\ ${ }^{1}$ Plymouth Marine Laboratory (NERC), Citadel Hill, Plymouth PL1 2PB, United Kingdom \\ ${ }^{2}$ School of Pure and Applied Biology, University of Wales College of Cardiff, PO Box 915, Cardiff CF1 3TL, United Kingdom
}

\begin{abstract}
Marine mussels Mytilus edulis (L.) of different ages were exposed to copper $\left(50 \mu g \mathrm{l}^{-1}\right)$ for up to $6 \mathrm{~d}$ and then transferred back to clean seawater. Copper exposure induced lysosomal destabilisation in the digestive cells of mussels of all ages. However, the mussel's ability to restore lysosomal integrity declined with increasing age. Lipid in the digestive cells of all mussels was associated with lysosomes after $6 \mathrm{~d}$ of copper exposure but its distribution returned to normal in all but the oldest mussels following reimmersion in clean seawater. The lipofuscin content of the digestive glands of all the mussels remained unchanged during copper exposure but increased in the oldest mussels following reimmersion in seawater. These findings indicate that mussels of all ages display a similar susceptibility to stress, but their capacity to recover and hence adapt to environmental changes declines with increasing age.
\end{abstract}

\section{INTRODUCTION}

There is little information on the relationship between age and stress response and recovery in mussels. As mussels are iteroparous organisms whose reproductive effort and gamete production increase with age (Bayne 1976, Bayne et al. 1983), an increase in their susceptibility to, and a decline in their ability to recover from, environmental stress would have deleterious consequences for the population and ultimately for the species. Furthermore, in view of the widespread use of mussels as environmental sentinels, it would be important to take account of any age-related differences in their response to stress and subsequent recovery.

Copper is a common pollutant of the marine environment and it induces cellular reactions in mussels by reacting with the structural and enzymic components of cell membranes, and successively with soluble enzymes, metabolites and organelles. Copper accumulated in the digestive gland cells of mussels has a half-life of about $9 \mathrm{~d}$ (Viarengo et al. 1985). Excess

\footnotetext{
- Present address: Royal Commission on Environmental Pollution, Church House, Great Smith Street, London SW1P 3BZ, United Kingdom
}

copper ions stimulate the synthesis of metallothioneins which are concentrated in the digestive cell lysosomes. The copper ions are detoxified by binding to the sulphydryl groups of these metallothioneins. Lysosomes containing the metallothioneins are transformed into residual bodies which may be stored or exocytosed thus eliminating the copper (Viarengo 1989).

Copper ions also stimulate oxyradical production and lipid peroxidation in the digestive gland of mussels, resulting in elevated levels of malondialdehyde (MDA) and lipofuscin, the latter being detected in lysosomes (Viarengo et al. 1990). Lipofuscin traps copper ions thus contributing to their detoxication (George \& Viarengo 1985, Viarengo 1989). Consequently, the lysosomal vacuolar system, which is well developed in the molluscan digestive gland, plays a vital and major role in the detoxication and elimination of copper.

If the copper sequestering capacity of the lysosomes becomes overloaded, the excess copper ions can cause much disruption at the cellular level. They can: disrupt cell membranes by catalysing lipid peroxidation reactions; inhibit sulphydryl group enzymes such as DNA and RNA polymerases, either by direct binding or by decreasing the level of antioxidants, particularly glutathione (GSH) (Viarengo et al. 1990); reduce the 
synthesis and increase the catabolism of proteins; destabilise lysosomal membranes, resulting in the possible release of hydrolytic enzymes and also leading to autophagy (Viarengo 1989). In addition, exposure of mussels to a copper and diesel oil mixture has been shown to result in increased levels of unsaturated neutral lipids in the digestive cells of mussels (Capuzzo \& Leavitt 1988, Lowe 1988, Moore 1988).

The objective of this study was to examine the influence of age on mussels' response to and recovery from copper exposure. Lysososomal membrane stability and levels of unsaturated neutral lipids and lipofuscin in digestive gland cells were the indices measured.

\section{MATERIALS AND METHODS}

Experimental details. Mytilus edulis (L.) of the 3 age groups, $2-4,6-8$ and $\geq 10 \mathrm{yr}$, were collected from Beggar's Island near Plymouth (UK) in July 1988. They were selected on the basis of a von Bertalanffy growth curve (a revised version of the curve by Bayne \& Worrall 1980) relating shell length to age for this population. The mussels were acclimated for $10 \mathrm{~d}$ in polypropylene tanks through which aerated, filtered, recirculating seawater at $12 \pm 1{ }^{\circ} \mathrm{C}$ and $33 \pm 1 \%$ salinity flowed continuously. They were fed ad libitum on the alga Phaeodactylum tricornutum during the acclimation period after which feeding was terminated and the seawater filtered to remove organic matter, thus maximising the bioavailability of copper.

The experimental mussels (14 per age group and sampling time) were exposed to $50 \mu \mathrm{g}$ copper $\mathrm{l}^{-1}$ in a flow-through seawater system. The dosing rate of the copper stock solution was based on the mussels' biomass and was adjusted as mussels were sacrificed. Vigorous aeration of the seawater ensured a homogeneous distribution of copper, and a build-up of copper in the tanks was minimised by cleaning the tanks every 2 d. Faeces were removed daily to reduce the likelihood of copper binding to the organic matter therein.

Groups of 14 mussels of each age group were sacrificed after 1, 3 and $6 \mathrm{~d}$ exposure to copper The remaining mussels were transferred to clean seawater, fed for $3 \mathrm{~d}$ to encourage depuration of copper and facilitate recovery, and starved for a further $3 \mathrm{~d}$ to purge the gut before the mussels were sacrificed. Control mussels $(n=14)$ of each age group were sampled at 0,6 and $12 \mathrm{~d}$.

Portions ( 3 to $4 \mathrm{~mm}^{3}$ ) of digestive glands of all the mussels sampled were taken to determine their copper content. Further portions ( 3 to $4 \mathrm{~mm}^{3}$ ) were removed for cytochemical determination of lysosomal membrane stability and levels of unsaturated neutral lipids and lipofuscin. These tissues were placed on aluminium chucks, quenched in hexane $\left(-70^{\circ} \mathrm{C}\right)$, doublewrapped in parafilm and stored at $-70^{\circ} \mathrm{C}$.

Copper analysis. Analysis of the copper content of mussel digestive glands was based on the methods of Bryan \& Hummerstone $(1971,1977)$ and involved acid digestion of groups of 7 portions of digestive gland per age group and sampling time. This was followed by atomic absorption using a Pye Unicam SP9 spectrophotometer at a wavelength of $324.8 \mathrm{~nm}$ with an airacetylene flame, background correction and external standards. Recoveries of copper were checked by the standard additions method. The copper concentrations, expressed as $\mu \mathrm{g} \mathrm{g}^{-1}$ wet $\mathrm{wt}$, were inversely transformed, as the standard deviations of these data were proportional to the square of their means, and tested for significant differences at the $5 \%$ level using a 2 -way analysis of variance.

Cytochemical determinations. Lysosomal stability: Cryostat sections $(10 \mu \mathrm{m})$ of digestive glands of all the mussels were reacted for lysosomal membrane stability based on the cytochemical latency of $\beta-\mathrm{N}$ acetylhexosaminidase (NAH), as described previously (Moore 1988). Twelve assessments of labilisation period were made in duplicate sections for each mussel using a Zeiss microscope $(\times 400)$. The results were tested for significant differences at the $5 \%$ level using the non-parametric Friedman's and KruskalWallis tests.

Unsaturated neutral lipids: Unsaturated neutral lipid levels were determined in $10 \mu \mathrm{m}$ fixed cryostat sections of digestive glands using the Oil Red $O$ reaction (Bancroft 1967). Twenty measurements per mussel (10 per duplicate section) were made at random in the apical region of the digestive tubules at $530 \mathrm{~nm}$, using a Vickers M85 scanning integrating microdensitometer $\left(\times 400\right.$; mask area $=130 \mu \mathrm{m}^{2}$; measuring beam diameter $=0.5 \mu \mathrm{m}$; slit width $=30$ ). The results were logarithmically transformed to correct for unequal variances and analysed using a 2 -way analysis of variance at the $5 \%$ level.

Lipofuscin: Fixed cryostat sections $(10 \mu \mathrm{m})$ of digestive glands of control ( $0 \mathrm{~d}$ ) and experimental mussels were stained for lipofuscin using the Schmorl reaction (Bancroft 1967) and stored in the dark until measurements were made. The area and lipofuscin content of each of 6 digestive tubules ( 3 per duplicate section), selected at random, were measured for each mussel using the Kontron M14 image analyser interfaced to a Reichert Polyvar microscope at $\times 800$ magnification. Each lipofuscin reading was divided by the area of the tubule in which it was determined, and was expressed as machine units of absorbance. The data were inversely transformed and analysed using a 2-way analysis of variance at the $5 \%$ level. 


\section{RESULTS}

\section{Tissue copper concentration}

Initially, copper concentrations in the digestive glands of control mussels differed with age, being highest in the youngest mussels and lowest in the oldest mussels (Fig. 1). However, these differences were reduced at subsequent sampling times ( 6 and $12 \mathrm{~d}$ ). Copper accumulated only in the oldest mussels after $1 \mathrm{~d}$ exposure $(p \leq 0.05)$ but afterwards it increased in the digestive glands of all mussels $(p \leq 0.05)$. Following reimmersion in clean seawater for $6 \mathrm{~d}$, copper concentrations declined in all mussels, to levels found in the $3 d$ copper-exposed mussels $(p>0.05)$. Throughout the experiment copper concentrations were highest in the youngest mussels.

\section{Lysosomal membrane stability}

Latent activities of NAH were similar in the digestive cells of all control mussels at each sampling time (Fig. 2). The labilisation period of NAH in all mussels remained unchanged following initial copper exposure but subsequently declined sharply $(p \leq 0.05)$. A dramatic increase in the enzyme latency in each age group was recorded $6 \mathrm{~d}$ after reimmersion in clean seawater $(p \leq 0.05)$. However, the latent activity of NAH in the oldest mussels was still depressed relative to that in the younger age groups $(p \leq 0.05)$.

\section{Unsaturated neutral lipids}

Unsaturated neutral lipids were present in the digestive cells of the control mussels as droplets. There was no consistent pattern in lipid levels among the mussels

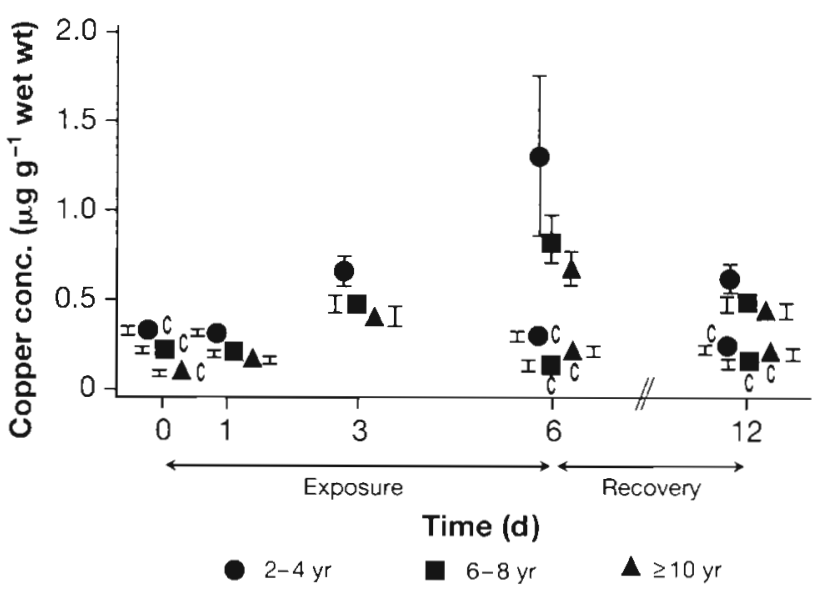

Fig. 1. Mytilus edulis. Copper concentrations in the digestive gland cells of mussels of different ages exposed to copper and subsequently immersed in 'clean' seawater. Means (n $=14) \pm 95 \%$ confidence intervals are shown. C: controls

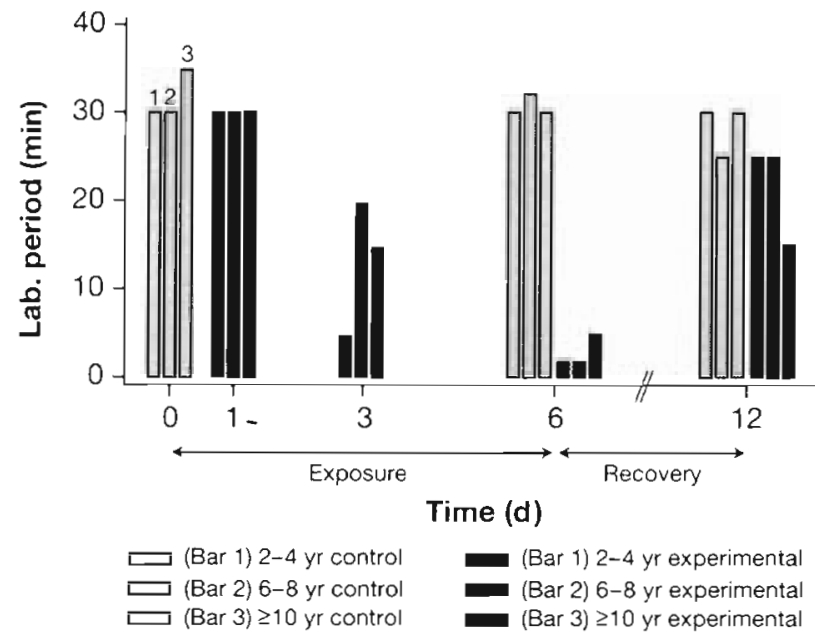

Fig. 2. Mytilus edulis. Effects of copper exposure and subsequent immersion in 'clean' seawater on the labilisation period of latent NAH in the digestive cell lysosomes of mussels of different ages. Medians $(n=14)$ are shown

of different age groups (Fig. 3). Lipid content in the youngest mussels increased following 3 and $6 \mathrm{~d}$ copper exposure while levels in the oldest mussels remained relatively constant throughout the experiment. Lipid levels in the 6-8 yr mussels fluctuated, increasing after $1 \mathrm{~d}$ exposure and again after $6 \mathrm{~d}$. Lipid levels were consistently higher in the youngest mussels than in the other age groups whose lipid levels were similar. Following $6 \mathrm{~d}$ copper exposure, lipid in the digestive cells of all mussels was associated with enlarged lysosomes, and the number of cytoplasmic lipid droplets increased at this time. The lipid content of the 2-4 and $6-8$ yr mussels declined following reimmersion in clean seawater and for mussels of each age group was

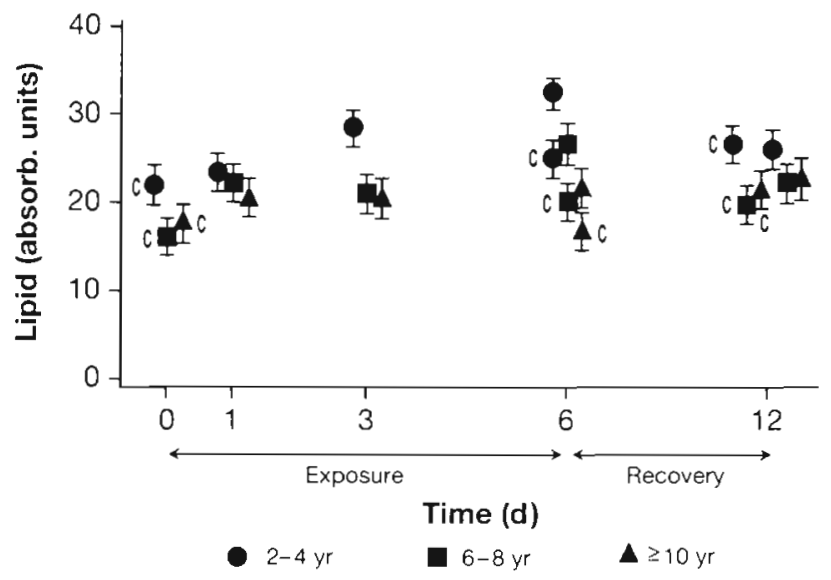

Fig. 3. Mytilus edulis. Effects of copper exposure and subsequent immersion in 'clean' seawater on the unsaturated neutral lipid content of the digestive cells of mussels of different ages. Means $(n=14) \pm 95 \%$ confidence intervals are shown. C: controls 


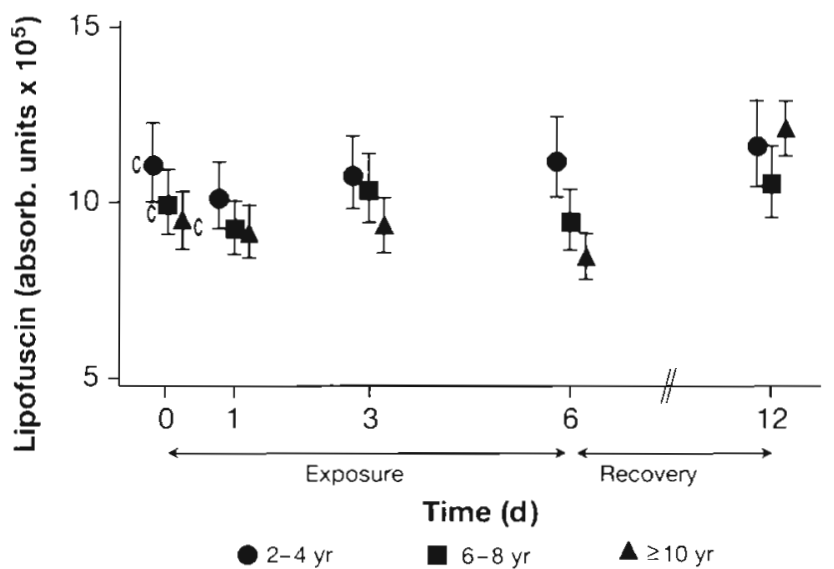

Fig. 4. Mytilus edulis. Effects of copper exposure and subsequent immersion in 'clean' seawater on the lipofuscin content of the digestive cells of mussels of different ages. Means $(\mathrm{n}=14) \pm 95 \%$ confidence intervals are shown. C: controls

similar to that of their respective controls at this time. The lipid levels in the oldest mussels remained relatively constant throughout the exposure and recovery periods. Lipids remained associated with lysosomes in the oldest mussels only.

\section{Lipofuscin}

Lipofuscin was detected in the secondary and tertiary lysosomes of the mussel digestive cells. There were no marked age-related differences in the lipofuscin content of the controls ( $p>0.05$ ) (Fig. 4). Lipofuscin levels were relatively constant for all mussels throughout the experiment, with the exception of the oldest mussels in which lipofuscin increased sharply $6 \mathrm{~d}$ after reimmersion in clean seawater $(\mathrm{p} \leq 0.05)$.

\section{DISCUSSION}

Initial age-related differences in the copper concentrations of the control mussels might reflect differences in the field (i.e. higher copper concentrations in the youngest mussels) which had not been negated during the acclimation period. The age-related decline in the extent of copper accumulation in mussel digestive glands, observed in this experiment, has been recorded previously in a study involving mussels of sizes equivalent to the youngest and oldest mussels in this study (Ritz et al. 1982). Copper concentrations in all mussels declined following reimmersion of the mussels in seawater.

Copper analysis of the mussel digestive glands permitted direct comparison of copper concentrations with cellular reactions in this organ. Accumulation of copper induced lysosomal destabilisation in all mussels Generally, the degree of destabilisation reflected the copper concentration in the digestive gland and was not related to the mussel's age. Secondary lysosomes in the digestive glands of all the mussels appeared enlarged after $6 \mathrm{~d}$ copper exposure. These reactions are indicative of autophagy.

The restoration of lysosomal integrity in the $2-4$ and $6-8$ yr mussels following $6 \mathrm{~d}$ reimmersion in clean seawater appears to be related to these mussels' ability to excrete copper from their digestive glands, as demonstrated previously by Moore et al. (1984). The $\geq 10$ yr mussels, however, showed only partial recovery of lysosomal integrity despite a similar decline in copper concentration in their digestive glands. This suggests that the oldest mussels are less able than younger ones to recover from copper-induced stress and will therefore suffer greater autophagic breakdown of their tissues.

The slight increases in the lipid content of the digestive cells of all the mussels following exposure to copper for $1 \mathrm{~d}$ were detected in the cytoplasm and were not associated with lysosomes. It seems unlikely, therefore, that this change constituted an autophagic reaction, particularly as the copper concentrations in the digestive glands of these mussels remained generally similar to those of the controls

The youngest mussels were the first to show an increase in lipid content (after $3 \mathrm{~d}$ copper exposure) and this probably reflected the copper concentration in their digestive glands which was higher than in other age groups at this time. The increase in lipid levels in the $6-8$ yr mussels only after $6 d$, when the copper concentration in their digestive glands was similar to that measured in the 2--4 yr mussels after $3 \mathrm{~d}$ exposure, suggests that this response is dependent upon a certain level of copper being reached in the digestive gland and is not age-dependent, at least in mussels up to $8 \mathrm{yr}$ of age. The association of lipids with enlarged lysosomes in the 2-4 and 6-8 yr mussels following $6 \mathrm{~d}$ copper exposure indicates that copper has induced autophagy in these animals and this is consistent with the disruption of lysosomal integrity seen in these mussels at this time.

Lysosomal accumulation of unsaturated neutral lipids in the digestive cells coincident with a reduction in hydrolase latency in enlarged secondary lysosomes has been demonstrated previously in small mussels contaminated by polyaromatic hydrocarbons, polychlorinated biphenyls and metals (Capuzzo \& Leavitt 1988, Lowe 1988, Moore 1988).

Enlargement of lysosomes in the digestive glands of $\geq 10 \mathrm{yr}$ mussels following $6 \mathrm{~d}$ copper exposure is indicative of autophagy. This reaction has been induced by a lower concentration of copper than was found to merit the same response in the younger mussels. It is 
possible, therefore, that the oldest mussels are more susceptible than the younger ones to autophagy induced by copper.

The decline in the lipid content of the digestive cells of the 2-4 and 6-8 yr mussels to control levels and its presence in the cytoplasm as droplets after $6 \mathrm{~d}$ reimmersion in clean seawater indicates recovery in these mussels following excretion of copper from their digestive glands. The persistence of the lysosomal accumulation of lipids in the oldest mussels, despite a reduction in the copper concentration in their digestive glands, suggests that these mussels are less able to recover from the autophagic reactions induced by copper than the younger mussels.

The absence of any significant changes in the levels of lipofuscin in the digestive gland cells of all mussels during copper exposure means that lipid peroxidation was not induced despite the promotion of autophagy and disruption of lysosomal integrity. Increased concentrations of lipofuscin in the digestive cells have been reported previously for mussels exposed to copper (Viarengo et al. 1987, 1990) and other metals (Regoli 1992) in the laboratory and in the field. However, the copper concentrations in the digestive glands of these mussels were higher than those measured in the present study.

The dramatic rise only in lipofuscin levels in the oldest mussels after 6 d reimmersion in clean seawater ( $p \leq 0.05)$ suggests that these mussels are more susceptible to lipid peroxidation. This is consistent with the persistence of autophagic reactions in the oldest mussels and with previous observations of an age-related decline in the level of the antioxidant, glutathione, in mussel digestive cells (Viarengo et al. 1991).

Lysosomes in mussel digestive cells are a recognised site for oxyradical generation (Winston et al. 1991), hence the older mussels' loss of ability to recover may well be linked to radical-induced damage of their lysosomes by copper ions, coupled with the loss of intralysosomal protective capability.

Acknowledgements. This work was supported in part by a NERC postgraduate studentship grant to L.M.H. and a NATO Collaborative Research Grant (R.0108/88) to M.N.M., A. Viarengo and G. Winston.

\section{LITERATURE CITED}

Bancroft, J. D. (1967). An introduction to histochemical technique. Butterworths, London

Bayne, B. L. (1976). Aspects of reproduction in bivalve molluscs. In: Wiley, M. (ed.) Estuarine processes, Vol. I. Academic Press, New York, p. 432-448

Bayne, B. L., Salkeld, P. N., Worrall, C. M. (1983). Reproductive effort and value in different populations of the marine mussel, Mytilus edulis L. Oecologia 59: 18-26
Bayne, B. L., Worrall, C. M. (1980). Growth and production of mussels Mytilus edulis from two populations. Mar. Ecol. Prog. Ser. 3: 317-328

Bryan, G. W., Hummerstone, L. G. (1971). Adaptation of the polychaete Nereis diversicolor to estuarine sediments containing high concentrations of heavy metals. I. General observations and adaptation to copper $\mathrm{J}$ mar. biol. Ass. U.K. 51: $845-863$

Bryan, G. W., Hummerstone, L. G. (1977). Indicators of heavymetal contamination in the Looe estuary (Cornwall) with particular regard to silver and lead. J. mar biol. Ass. U.K. 57: $75-92$

Capuzzo, J. M., Leavitt, D. F. (1988). Lipid composition of the digestive glands of Mytilus edulis and Carcinus maenas in response to pollutant gradients. Mar. Ecol. Prog. Ser. 46: $139-145$

George, S. G., Viarengo, A. (1985). A model for heavy metal homeostasis and detoxication in mussels. In: Vernberg, F. J., Thurberg, F. P., Calabrese, A., Vernberg, W. B. (eds.) Marine pollution and physiology: recent advances. University of South Carolina Press, Columbia, p. 125-143

Lowe, D. M. (1988). Alterations in cellular structure of Mytilus edulis resulting from exposure to environmental contaminants under field and experimental conditions. Mar. Ecol. Prog. Ser. 46: 91-100

Moore, M. N. (1988). Cytochemical responses of the lysosomal system and NADPH-ferrihaemoprotein reductase in molluscan digestive cells to environmental and experimental exposure to xenobiotics. Mar. Ecol. Prog. Ser. 46 : $81-89$

Moore, M. N., Widdows, J., Cleary, J. J., Pipe, R. K., Salkeld, P. N., Donkin, P., Farrar, S. V., Evans, S. V., Thomson, P. E. (1984). Responses of the mussel Mytilus edulis to copper and phenanthrene: interactive effects. Mar. environ. Res. 14: $167-183$

Regoli, F. (1992). Lysosomal responses as a sensitive stress index in biomonitoring heavy metal pollution. Mar Ecol. Prog. Ser. 84: 63-69

Ritz, D. A., Swain, R., Elliott, N. G. (1982). Use of the mussel Mytilus edulis planulatus (Lamarck) in monitoring heavy metal levels in seawater Aust. J. mar. Freshwat. Res. 33: 491-506

Viarengo, A. (1989). Heavy metals in marine invertebrates: mechanisms of regulation and toxicity at the cellular level. Rev. Aquat. Sci. 1. 295-317

Viarengo, A., Canesi, L., Pertica, M., Livingstone, D. R., Orunesu, M. (1991). Age-related lipid peroxidation in the digestive gland of mussels: the role of the antioxidant defence systems. Experientia 47:454-457

Viarengo, A., Canesi, L., Pertica, M., Poli, G., Moore, M. N., Orunesu, M. (1990). Heavy metal effects on lipid peroxidation in the tissues of Mytilus galloprovincialis Lam. Comp. Biochem. Physiol. 97 C: 37-42

Viarengo, A., Moore, M. N., Mancinelli, G., Mazzucotelli, A., Pipe, R. K., Farrar, S. V. (1987). Metallothioneins and lysosomes in metal toxicity and accumulation in marine mussels: the effect of cadmium in the presence and absence of phenanthrene. Mar. Biol. 94: 251-257

Viarengo, A., Moore, M. N., Pertica, M., Mancinelli, G., Zanicchi, G., Pipe, R. K. (1985). Detoxification of copper in the cells of the digestive gland of mussel: the role of lysosomes and thioneins. Sci. total Environ. 44: 135-145

Winston, G. W., Moore, M. N., Straatsburg, 1., Kirchin, M. A. (1991). Decreased stability of digestive gland lysosomes from the common mussel Mytilus edulis $\mathrm{L}$. by in vitro generation of oxygen-free radicals. Arch. environ. Contam. Toxicol. 21.401-408 